\title{
Research on Education Internet and New Forms of Businesses in the Background of Big Data
}

\author{
Zhaoyang Wu, Duozhong Xu, Wenxiu Li, Ma Jie \\ Normal University Xining, Xining 810036, Qinghai, China. \\ Project: Research on Education Internet and New Forms of Businesses in the Background of New Coronavirus \\ Pandemic(2020XTW006)
}

\begin{abstract}
With the continuous development of information technology and the continuous implementation of new curriculum reforms, people are paying more and more attention to basic education. The "Internet +" education reform under the background of big data has become an important part of improving the quality of basic education in China and promoting education equity. Ways and means. Based on big data technology and the application of "Internet + ", this article discusses in detail its significance in junior high school teaching, and provides some useful reform suggestions for the development of my country's junior high school education, hoping to improve the quality of my country's basic education.
\end{abstract}

Keywords: Big Data Background; Junior High School Education; Internet+; New Business Development

Compulsory education is the foundation of our country and an important measure to protect people's basic education. However, because our country's population base is too large, coupled with the differences in regional economic development, the distribution of educational resources is unbalanced, which greatly limits it The development of basic education in our country.

\section{The importance of big data technology and "Internet +" application in basic education \\ 1.1 Alleviated the imbalance of regional education resources}

There are certain differences in basic education facilities and teaching resources across the country in terms of quantity and quality, and even some economically developed areas in the same city will have more obvious educational differences, and the reason for this phenomenon is Because basic education requires not only a large amount of infrastructure construction, but also the establishment of an excellent teacher education team, but the limited teacher resources cannot satisfy the current huge education market. With the development of information technology, various high-quality "Internet + education" applications are emerging. The use of online teaching can effectively alleviate the tight demand for high-quality teacher resources, so that more students can receive the teachings of excellent teachers, and effectively improve our country's foundation The quality of education and teaching.

\subsection{Enriched teaching resources}

Big data technology can be applied to many fields. In the field of basic education, big data technology can help teachers find the teaching resources they need faster, better, and more accurately, and make personalized recommendations based on their own teaching needs., Which greatly reduces the workload of teachers looking for teaching resources and helps teachers put more energy into actual teaching. In addition, teachers can also use the Internet to spread knowledge and learn more advanced teaching and education experience, so as to continuously improve and upgrade their own teaching level, which is an indispensable part of the future development of basic education in my country.

\subsection{Promote the personalized development of students}

The combination of "Internet + " application and big data technology can create a more humane teaching platform.

Copyright(C) 2020 Zhaoyang Wu et al.

doi: 10.18686/ahe.v4i10.2927

This is an open-access article distributed under the terms of the Creative Commons Attribution Non-Commercial License (http://creativecommons. org/licenses/by-nc/4.0/), which permits unrestricted non-commercial use, distribution, and reproduction in any medium, provided the original work is properly cited. 
For junior high school students, this new teaching situation can help students use online time more efficiently, reduce their addiction to online games, and train students to be good The self-discipline ability promotes students to develop a good habit of self-study. At the same time, this online learning platform based on big data technology can make personalized teaching recommendations based on students' own conditions, help students accurately discover their own learning deficiencies, quickly improve their own learning level, and put "people-oriented" in education and teaching. Play to the extreme.

\section{Educational development and reform measures based on big data technology and "Internet +"}

\subsection{Increasing access to the Internet for education in poor areas}

There are several ways to improve the quality of regional education and teaching. One is to increase the basic investment in education and use Internet technology to introduce high-quality teaching resources. The second is to establish a high-quality teacher education team to improve the quality of education and teaching. The third is to attach importance to both of the above. Therefore, for poverty-stricken areas to get out of the educational trough as soon as possible, it is most cost-effective to build basic education facilities first. Therefore, strengthening the construction of technical education facilities in poor areas and increasing students' access to the Internet can quickly improve the quality of local teaching.

\subsection{Increasing the resource input of the online course education platform}

Nowadays, only a small number of famous teachers have recorded online public courses, and the subjects and teaching content involved are not complete, which cannot meet the current needs of people for high-quality educational resources. Therefore, the resource input of the online course education platform should be increased. First, encourage high-quality teachers from all schools to join the recording of online public courses. Second, the local government and education department can give teachers some financial subsidies to improve the quality of high-quality teacher video teaching. Finally, the promotion of education platforms should be increased to attract high-quality capital to further meet people's demand for high-quality educational resources.

\subsection{The organic combination of online education and classroom education}

As the popularity of online education continues to increase, people are gradually discovering the advantages of online education, but traditional classroom teaching also has an irreplaceable role. For example, students can cultivate good interpersonal skills in classroom teaching, and teachers can teach students More effective education management, training students to have good study habits and self-discipline. Therefore, teachers should organically combine online education with classroom teaching, use big data technology to assist teachers in understanding the basic situation of students, and promote the reform of classroom teaching content based on student feedback, making classroom teaching more efficient.

\subsection{Increasing technical investment in big data technology and "Internet +" education applications}

Nowadays, big data technology and "Internet +" education applications are still in their infancy, and there are still many problems that restrict and affect the rapid development of online education. Relevant technical workers and educators should increase their research investment in this area. The work efficiency of Internet infrastructure increases the speed of information dissemination and enhances the online teaching experience. Reduce the cost of entering Internet learning, expand the scope of influence of Internet education, and provide relevant preferential treatment and support in policies.

\section{Conclusion}

In the context of big data, the application of "Internet + " technology to basic education can effectively change the imbalance of educational resources in China and help more students learn high-quality educational content. It is a favorable technology that benefits the country and the people. Relevant researchers and government workers should increase funding and technology investment in this area, so that China has a more complete Internet teaching environment as soon as possible, and make unremitting efforts to improve the quality of education in China.

\section{References}

1. Chen XP, Gao J. On the transformation of traditional textbook publishing industry under the background of big data in the “Internet +" era. Science Technology and Publishing 2015; (07): 117-122.

2. Liu Q, Ding LT. Research brief on the innovation of the "internet + continuing education" model in the context of the big data era. Journal of Higher Continuing Education 2016; (3): 6 "10, 2" total 6 pages.

3. Peng CJ. Research on the "internet +" creative education talent training model in the context of big data. China Business Forum 2016; (27): 191-192. 